\title{
Tunable Band Gap Energy of Mn-Doped ZnO Nanoparticles Using the Coprecipitation Technique
}

\author{
Tong Ling Tan, Chin Wei Lai, and Sharifah Bee Abd Hamid \\ Nanotechnology \& Catalysis Research Centre (NANOCAT), Deputy Vice Chancellor (Research \& Innovation), \\ Institute of Graduate Studies, University of Malaya, 50603 Kuala Lumpur, Malaysia \\ Correspondence should be addressed to Sharifah Bee Abd Hamid; sharifahbee@um.edu.my
}

Received 14 October 2013; Accepted 17 December 2013; Published 28 January 2014

Academic Editor: Clare C. Byeon

Copyright (C) 2014 Tong Ling Tan et al. This is an open access article distributed under the Creative Commons Attribution License, which permits unrestricted use, distribution, and reproduction in any medium, provided the original work is properly cited.

A simple coprecipitation technique was introduced to form manganese ( $\mathrm{Mn}$ ) doped on zinc oxide $(\mathrm{ZnO})$ nanoparticles effectively. Based on our morphological studies, it was revealed that mean particle size was increased while bigger agglomeration of nanoparticles could be observed as the amount of concentration of Mn was increased. Interestingly, it was found that the position of the absorption spectra was shifted towards the lower wavelength (UV region) as correlated with the increasing of Mn dopants concentration into $\mathrm{ZnO}$ nanoparticles. This result inferred that optimum content of $\mathrm{Mn}$ doped into the $\mathrm{ZnO}$ nanoparticles was crucial in controlling the visible/UV-responsive of samples. In the present study, $3 \mathrm{~mol} \%$ of $\mathrm{Mn}$ dopants into the $\mathrm{ZnO}$ nanoparticles exhibited the better UV as well as visible light-responsive as compared to the other samples. The main reason might be attributed to the modification of electronic structure of $\mathrm{ZnO}$ nanoparticles via lattice doping of $\mathrm{Mn}$ ions into the lattice, whereas excessive $\mathrm{Mn}$ dopants doped on $\mathrm{ZnO}$ nanoparticles caused the strong UV-responsive due to the more $3 \mathrm{~d}$ orbitals in the valence band.

\section{Introduction}

Nowadays, most countries are facing environmental pollution problems and thus the awareness of people upon this matter was increased tremendously. Water is an essential source for human beings and it was shown that the demand of clean and safe drinking water is rising; therefore, the use of the nano semiconductor material on photocatalytic oxidation for oxidizing the toxic pollutant has become of great interest in recent material research field [1].

Zinc oxide $(\mathrm{ZnO})$ is an essential semiconductor with direct band gap of $3.3 \mathrm{eV}$ and high excitant binding energy of $60 \mathrm{meV}$. Due to its potential application in many areas such as optoelectronic devices, solar cells, chemical sensor, and photocatalyst hence, it has attracted the attention of more and more researchers and scientists to develop $\mathrm{ZnO}$ in the field of science and technology. In addition, $\mathrm{ZnO}$ is lower in cost and is environmental friendly as compared to other metal oxides [2]. Normally, $\mathrm{ZnO}$ is studied in nanoscale; this is probably due to the fact that the high surface area to mass ratio of nanoparticles could enhance the adsorption of organic pollutants on the surface of particles as compared to the bulk materials [1].
However, undoped $\mathrm{ZnO}$ nanoparticles have certain limitation on light absorption catalytic activity. It was revealed that $\mathrm{ZnO}$ has alarge band gap energy of about $3.3 \mathrm{eV}$ which can only absorb light within UV region. In addition, the fast recombination rate of photogenerated electron-hole pairs will also contribute to the limitation of photocatalytic activity. Thus, in order to enhance the optical, magnetic, and electrical properties of $\mathrm{ZnO}$, the transition metal-doped $\mathrm{ZnO}$ nanoparticles have been introduced. The modification of $\mathrm{ZnO}$ nanoparticles with impurity incorporation leads to possible application in UV optoelectronic and spin electronics [3]. Among the transition elements, $\mathrm{Mn}$ shows the maximum magnetic behaviors with electron effective mass $\sim 0.3 m_{e}\left(m_{e}=\right.$ free electron mass); a doping of $\mathrm{Mn}$ into the $\mathrm{ZnO}$ semiconductor host lattice may result in large injected spins and carrier which make it suitable to be applied as diluted magnetic semiconductor (DMSs) [4].

Actually, the term "doped" is used to modify the optical or magnetic properties of the host by adding impurities ions against the host lattice. The doping with $3 \mathrm{~d}$ metals such as $\mathrm{Mn}$, $\mathrm{Ni}, \mathrm{Fe}, \mathrm{Co}$, and $\mathrm{Cr}$ will increase the surface area and reduce the particle size of $\mathrm{ZnO}$ nanoparticles [5]. Mn is preferred for 
TABLE 1: Amounts of reactant required to prepare nanoparticles with different manganese concentrations.

\begin{tabular}{lcccccc}
\hline & \multicolumn{5}{c}{ Amounts added in mol for mol\% of $\mathrm{Zn}(\mathrm{OAc})_{2} \cdot 2 \mathrm{H}_{2} \mathrm{O}, \mathrm{Mn}(\mathrm{OAc})_{2} \cdot 2 \mathrm{H}_{2} \mathrm{O}$ and NaOH } \\
\hline Chemicals & 0 & 3 & 5 & 10 & 15 & 20 \\
$\mathrm{Zn}(\mathrm{OAc})_{2} \cdot 2 \mathrm{H}_{2} \mathrm{O}$ & 2.00 & 1.94 & 1.90 & 1.80 & 1.70 \\
$\mathrm{Mn}(\mathrm{OAc})_{2} \cdot 4 \mathrm{H}_{2} \mathrm{O}$ & 0.00 & 0.06 & 0.10 & 0.20 & 1.60 \\
$\mathrm{NaOH}$ & 2.00 & 2.00 & 2.00 & 2.00 & 0.30 & 0.40 \\
\hline
\end{tabular}

the doping of $\mathrm{ZnO}$ due to the fact that the delectron of $\mathrm{Mn}$ at $t_{2 g}$ level can easily overlap with the ZnO's valence bond as compared with other transition elements. There are various studies which showed, that Mn-doped semiconductors have influenced the physical, chemical, and structural properties of undoped $\mathrm{ZnO}$ nanoparticles. For example, the optical properties of undoped $\mathrm{ZnO}$ nanoparticles especially on the tuning of the band gap can be greatly improved at the nanoscale by optimum content of Mn doping [6, 7].

Currently, the synthesis of $\mathrm{Mn}$-doped $\mathrm{ZnO}$ nanoparticles can be through various types of methods such as wetchemical, sol-gel, coprecipitate, solid-thermal, and spray pyrolysis. In order to enhance the optical properties and obtain a small particle size, a search for alternative synthesis methods for efficiency $\mathrm{Mn}$ doping with $\mathrm{ZnO}$ nanoparticles has become the major interest of studies. The purpose of this work was to synthesize band gap energy tunable of $\mathrm{Mn}$-doped $\mathrm{ZnO}$ nanoparticles with high surface area for better photocatalytic performance using coprecipitation method. Zinc acetate $\left(\mathrm{Zn}(\mathrm{ac})_{2} \cdot 2 \mathrm{H}_{2} \mathrm{O}\right)$ and manganese acetate $\left(\mathrm{Mn}(\mathrm{ac})_{2} \cdot 4 \mathrm{H}_{2} \mathrm{O}\right)$ act as precursors and absolute ethanol was used as a solvent to synthesis $\mathrm{Mn}$-doped $\mathrm{ZnO}$ nanoparticles. Basically, the synthesis of electrostatically stable Mn-doped $\mathrm{ZnO}$ nanoparticles was performed in an alcoholic solution in order to avoid the formation of $\mathrm{ZnOH}$ [8].

\section{Experimental}

2.1. Materials. All the chemicals used were analytical grade and were used in this experiment without further purification. The chemicals used were zinc acetate dehydrate $\left(\mathrm{Zn}(\mathrm{OAc})_{2} \cdot 2 \mathrm{H}_{2} \mathrm{O}\right),>99.5 \%$, from Fluka), manganese acetate tetrahydrate, $\left(\mathrm{Mn}(\mathrm{OAc})_{2} \cdot 4 \mathrm{H}_{2} \mathrm{O},>98 \%\right)$, sodium hydroxide $(\mathrm{NaOH}, 98 \%)$, and absolute ethanol $\left(\mathrm{C}_{2} \mathrm{H}_{5} \mathrm{OH},>99 \%\right)$.

2.2. Synthesis Procedures of $\mathrm{Mn}$-Doped ZnO Nanoparticles. $\mathrm{Mn}$-doped $\mathrm{ZnO}$ nanoparticle was prepared by using solgel method [8]. Mn-doped $\mathrm{ZnO}$ nanoparticles were synthesized by the reaction of $\mathrm{Zn}^{2+}, \mathrm{Mn}^{2+}$, and $\mathrm{OH}^{-}$in an alcoholic medium (ethanol). For $5 \mathrm{~mol} \%$ of $\mathrm{Mn}$-doped $\mathrm{ZnO}$ nanoparticles, there were generally three solutions that needed to be prepared. The first solution contained $20 \mathrm{mM}$ of zinc acetate dehydrate $\left(\mathrm{Zn}(\mathrm{ac})_{2} \cdot 2 \mathrm{H}_{2} \mathrm{O}\right)$ in $10 \mathrm{~mL}$ of ethanol. The second solution consisted of $1.0 \mathrm{mM}$ of manganese acetate tetrahydrate $\left(\mathrm{Mn}(\mathrm{ac})_{2} \cdot 4 \mathrm{H}_{2} \mathrm{O}\right)$ in $10 \mathrm{~mL}$ of ethanol. Then, the next solution consisted of $20 \mathrm{mM}$ of $\mathrm{NaOH}$ in $10 \mathrm{~mL}$ of ethanol. These three solutions at first were heated to $50^{\circ} \mathrm{C}$. After heating, zinc acetate solution was poured into round bottom flask and then manganese acetate solution was added to it.
Zinc acetate and manganese acetate solution was again heated to $80^{\circ} \mathrm{C}$ with constant stirring for 30 minutes. Then, $\mathrm{NaOH}$ solution was added dropwise into the solution containing $\mathrm{Zn}(\mathrm{ac})_{2} \cdot 2 \mathrm{H}_{2} \mathrm{O}$ and $\mathrm{Mn}(\mathrm{ac})_{2} \cdot 4 \mathrm{H}_{2} \mathrm{O}$ along with reflux. The solutions were again heated to $60-65^{\circ} \mathrm{C}$ with magnetic stirring for $2 \mathrm{~h}$. After this, the solution was cooled to room temperature. The precipitate was formed and was washed several times with distilled water and then followed by ethanol. The purpose of washing precipitate with ethanol was to remove the unwanted salt and impurities.

To investigate the effect of different concentrations of Mn dopant ions on the physical, chemical, and optical properties of $\mathrm{Mn}$-doped $\mathrm{ZnO}$ nanoparticles, the same procedures as stated above were carried out for $3 \mathrm{~mol} \%, 10 \mathrm{~mol} \%, 15 \mathrm{~mol} \%$, and $20 \mathrm{~mol} \%$ of $\mathrm{Mn}$-doped $\mathrm{ZnO}$ nanoparticles. Table 1 below shows the amount of reactant required to prepare nanoparticles with different manganese concentrations.

2.3. Characterization. The effects of $\mathrm{Mn} / \mathrm{ZnO}$ on the composition, morphology, and optical properties of $\mathrm{Mn}$-doped $\mathrm{ZnO}$ nanoparticles were determined by various techniques. Elemental and chemical composition of $\mathrm{Mn}$-doped $\mathrm{ZnO}$ nanoparticles were carried out using a Scanning Electron Microscope-Energy Dispersive X-ray (SEM-EDX). Surface morphologies of $\mathrm{Mn}$-doped $\mathrm{ZnO}$ nanoparticles were carried out using a Scanning Electron Microscope (SEM). The SEM images are shown in the magnification of 10,000. FTIR analysis was performed using a FTIR spectroscopy Perkin Elmer spectrum GX model to obtain information about the chemical bonding and molecular structure in a sample. The optical absorption spectra of $\mathrm{Mn}$-doped $\mathrm{ZnO}$ nanoparticles were carried out using a UV-visible Spectrophotometer operating at a wavelength range of $300 \mathrm{~nm}$ to $500 \mathrm{~nm}$. Fluorescence spectrophotometer, CARY Eclipse, and Varian model were used to investigate the effect of different $\mathrm{Mn}$-doped contents on the optical emission properties of $\mathrm{Mn}$-doped $\mathrm{ZnO}$ nanoparticles.

\section{Results and Discussion}

3.1. Morphological Studies. The influence of different percentage of $\operatorname{Mn}(3,5,10,15$, and $20 \mathrm{~mol} \%)$ on the surface morphologies of $\mathrm{Mn}$-doped $\mathrm{ZnO}$ nanoparticles was studied by SEM which is shown in Figure 1. It can be seen that as the percentage of $\mathrm{Mn}$ doped increases, the grain size of the $\mathrm{ZnO}$ nanoparticles is also increasing (Table 2). From the SEM images, it can be seen that with above $15 \mathrm{~mol} \%$, the agglomeration increases. This may probably be related to the kinetic equilibrium process where the high concentration of $\mathrm{Mn}$ 


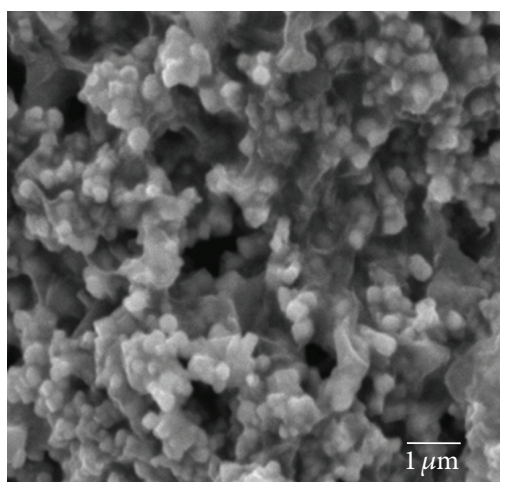

(a)

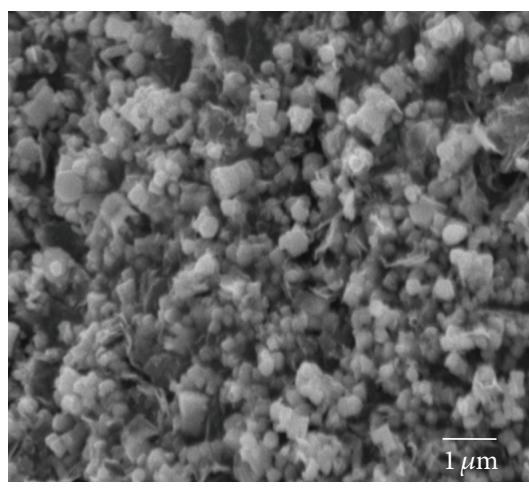

(b)

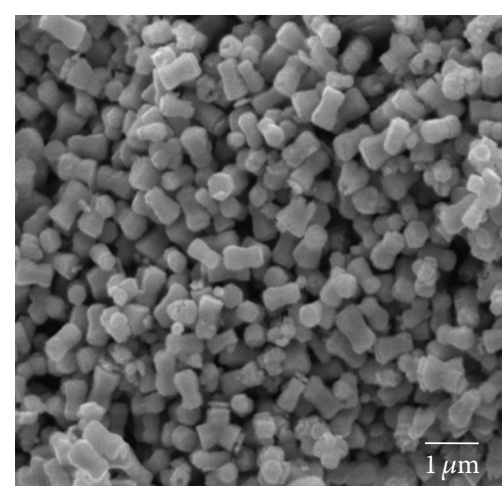

(c)

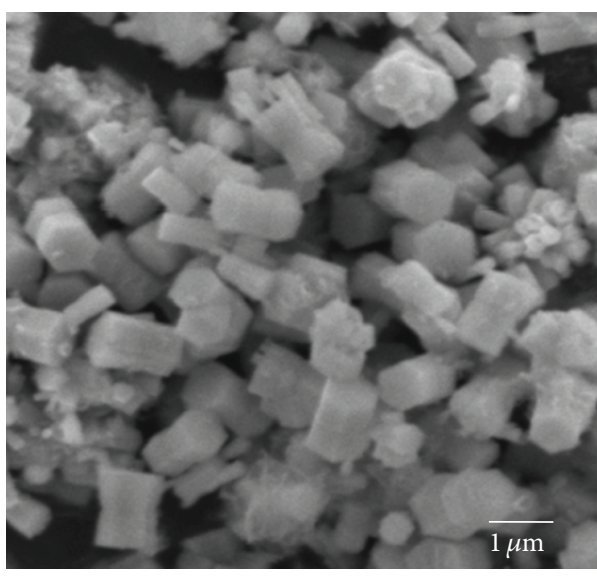

(d)

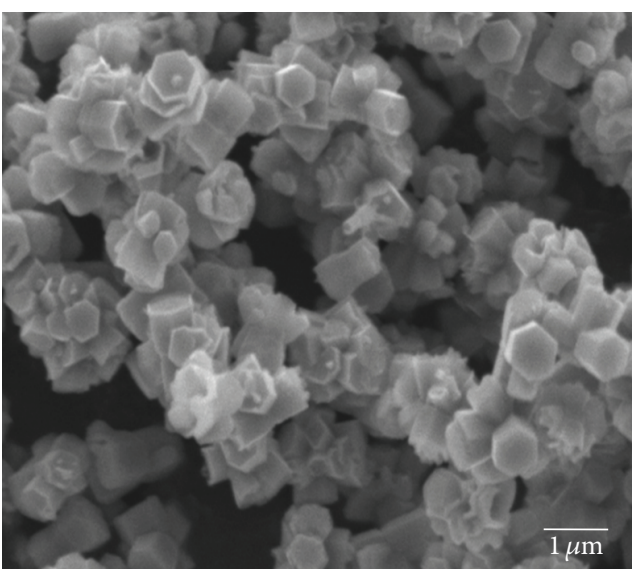

(e)

Figure 1: SEM images of Mn-doped ZnO nanoparticles with (a) $3 \mathrm{~mol} \%$, (b) $5 \mathrm{~mol} \%$, (c) $10 \mathrm{~mol} \%$, (d) $15 \mathrm{~mol} \%$, and (e) $20 \mathrm{~mol} \%$.

TABLE 2: The mean size obtained from different percentage of Mn doping in $\mathrm{ZnO}$ nanoparticles.

\begin{tabular}{lc}
\hline $\begin{array}{l}\text { Manganese dopant } \\
\text { concentration (mol\%) }\end{array}$ & Mean particle size $(\mathrm{nm})$ \\
\hline 3 & 157 \\
5 & 187 \\
10 & 245 \\
15 & 432 \\
20 & 509 \\
\hline
\end{tabular}

dopants could be nucleated with oxygen ions by itself and form bigger particles. Hence, it could be difficult for the Mn to be incorporated into $\mathrm{ZnO}$ lattice in higher concentration. As a conclusion, a lower dopant concentration of Mn-doped $\mathrm{ZnO}$ nanoparticles showed lower agglomeration and wellordered and small particles size distribution than the higher Mn dopant concentration [9].

3.2. Elemental and Chemical Composition Analysis. Figure 2 shows the EDX spectrum of $3 \mathrm{~mol} \%, 5 \mathrm{~mol} \%, 10 \mathrm{~mol} \%$, $15 \mathrm{~mol} \%$, and $20 \mathrm{~mol} \%$ of $\mathrm{Mn}$-doped $\mathrm{ZnO}$ nanoparticles. From the EDX spectrum, it can be seen that the amount of Mn element in the samples increased depending on the increasing $\mathrm{Mn}$ incorporation in the $\mathrm{ZnO}$ nanoparticles. The area of the corresponding spectral $\mathrm{K}$ lines gives the quantitative results of the $\mathrm{Mn} / \mathrm{Zn}$ ratio [10]. The elemental analysis for $\mathrm{O}, \mathrm{Mn}$, and $\mathrm{Zn}$ for each sample (3 mol\%, $5 \mathrm{~mol} \%$, $10 \mathrm{~mol} \%$, $15 \mathrm{~mol} \%$, and $20 \mathrm{~mol} \%$ ) was shown in Table 3.

3.3. FTIR Analysis. Various peaks corresponding to the main absorption bands can be seen from the FTIR spectrum on Figure 3. The broad absorption peak around $3376 \mathrm{~cm}^{-1}$, $3377 \mathrm{~cm}^{-1}$, and $3378 \mathrm{~cm}^{-1}$ represents the $\mathrm{O}-\mathrm{H}$ stretching of the hydroxyl group. The peak around $2900 \mathrm{~cm}^{-1}$ was due to $\mathrm{C}-\mathrm{H}$ (acetate) stretching [11]. Two absorption peaks are observed between 1650 and $1400 \mathrm{~cm}^{-1}$, corresponding to the asymmetric and symmetric stretching of the carboxyl group $(\mathrm{C}=\mathrm{O})$.

From the studies, the stretching mode of undoped $\mathrm{ZnO}$ is at $431 \mathrm{~cm}^{-1}$. In this work, for $\mathrm{Zn}_{1-x} \mathrm{Mn}_{x} \mathrm{O}(x=0.03,0.05$, $0.10,0.15$, and 0.20$)$, the values of absorption were found to be blueshifted at $443,450,462,470$, and $481 \mathrm{~cm}^{-1}$, respectively. Undoubtedly, this can prove that the $\mathrm{Zn}-\mathrm{O}-\mathrm{Zn}$ network was perturbed by the presence of $\mathrm{Mn}$ in its environment with the change in the peak position of the $\mathrm{ZnO}$ absorption bands [12].

3.4. Optical Studies. In this work, we obtained the wavelength for undoped $\mathrm{ZnO}$ and $3 \mathrm{~mol} \%, 5 \mathrm{~mol} \%, 10 \mathrm{~mol} \%$, and $15 \mathrm{~mol} \% \mathrm{Mn}$-doped $\mathrm{ZnO}$ nanoparticles. It was observed that 
TABLE 3: Mass \% of O, Mn, and $\mathrm{Zn}$ as determined by EDX analysis.

\begin{tabular}{|c|c|c|c|c|c|}
\hline \multirow{2}{*}{ Element } & \multicolumn{5}{|c|}{ Mass \% } \\
\hline & $3 \mathrm{~mol} \%$ & $5 \mathrm{~mol} \%$ & $10 \mathrm{~mol} \%$ & $15 \mathrm{~mol} \%$ & $20 \mathrm{~mol} \%$ \\
\hline $\mathrm{O}$ & 23.48 & 33.73 & 7.60 & 43.31 & 53.34 \\
\hline Mn & 3.26 & 4.66 & 9.51 & 15.23 & 20.97 \\
\hline $\mathrm{Zn}$ & 73.25 & 61.62 & 82.89 & 41.46 & 25.69 \\
\hline
\end{tabular}

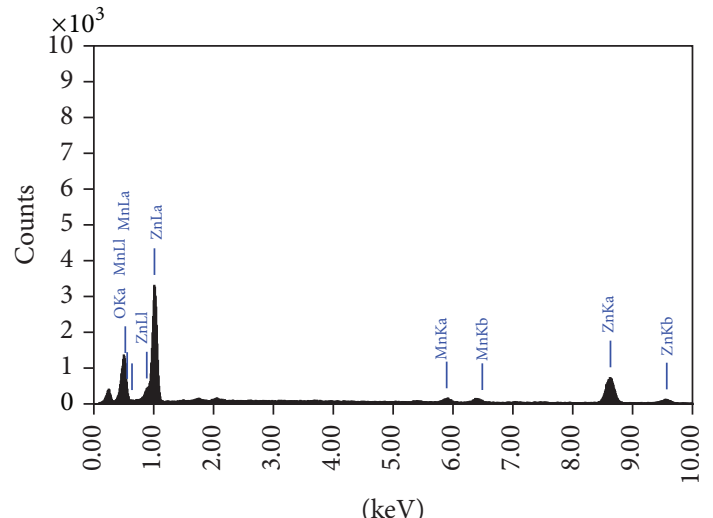

(a)

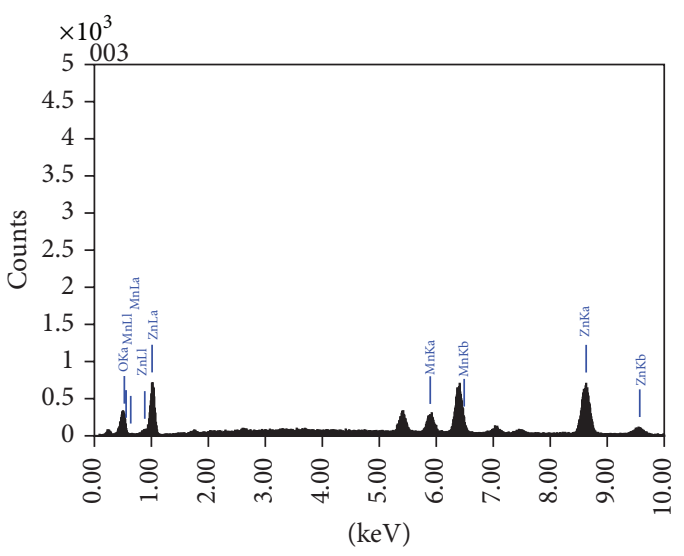

(c)

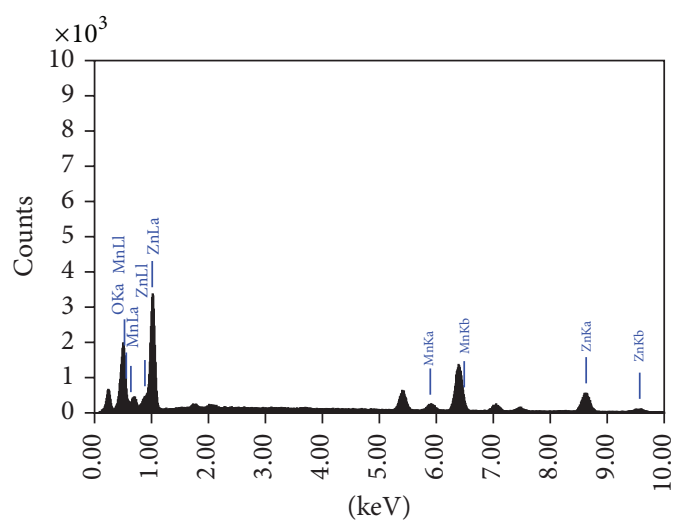

(b)

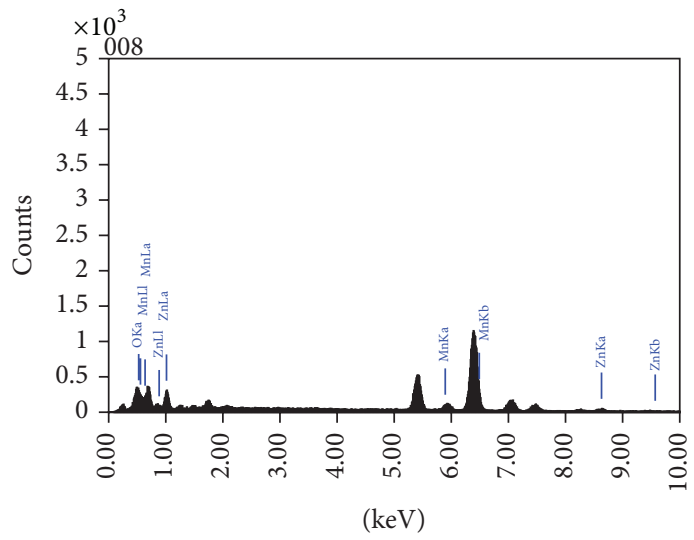

(d)

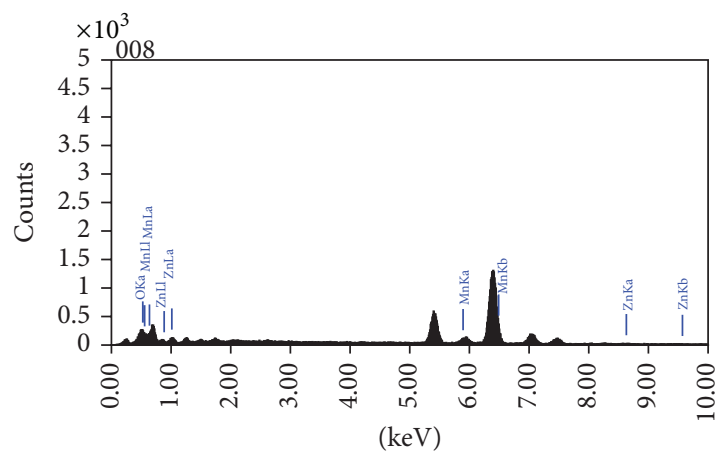

(e)

FIGURE 2: EDX spectrum of Mn-doped $\mathrm{ZnO}$ nanoparticles with (a) $3 \mathrm{~mol} \%$, (b) $5 \mathrm{~mol} \%$, (c) $10 \mathrm{~mol} \%$, (d) $15 \mathrm{~mol} \%$, and (e) $20 \mathrm{~mol} \%$. 


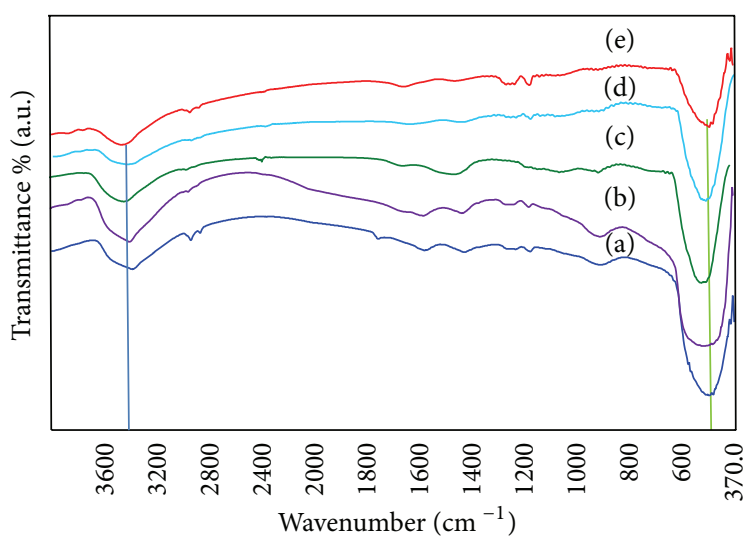

FIGURE 3: FTIR spectrum of Mn-doped $\mathrm{ZnO}$ nanoparticles with (a) $3 \mathrm{~mol} \%$, (b) $5 \mathrm{~mol} \%$, (c) $10 \mathrm{~mol} \%$, (d) $15 \mathrm{~mol} \%$, and (e) $20 \mathrm{~mol} \%$ of Mn dopant concentrations.

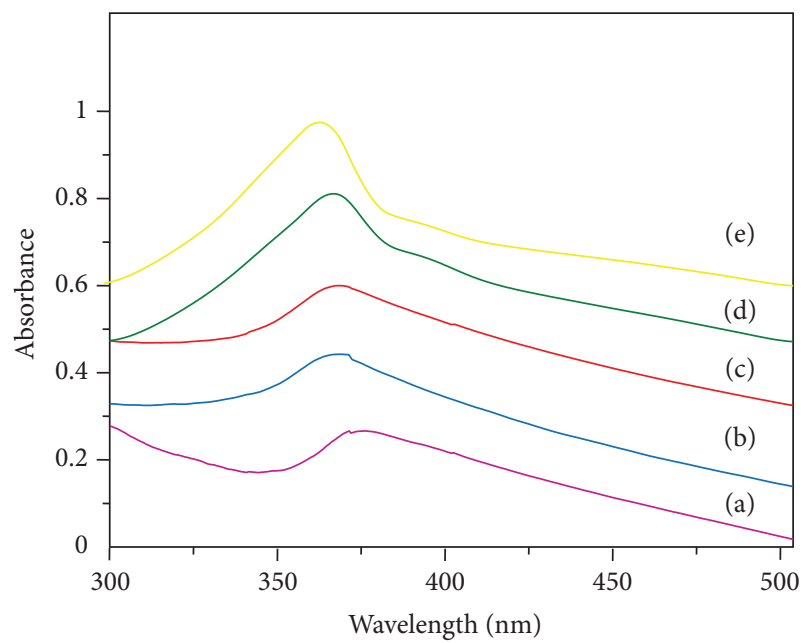

Figure 4: Absorbance spectrum of $\mathrm{Mn}$-doped $\mathrm{ZnO}$ nanoparticles with (a) pure $\mathrm{ZnO}$, (b) $3 \mathrm{~mol} \%$, (c) $5 \mathrm{~mol} \%$, (d) $10 \mathrm{~mol} \%$, and (e) $15 \mathrm{~mol} \%$.

the absorption edges of undoped $\mathrm{ZnO}$ and $3 \mathrm{~mol} \%, 5 \mathrm{~mol} \%$, $10 \mathrm{~mol} \%$ and $15 \mathrm{~mol} \%$ of Mn doping are 374.5, 370, 367, 365, and $362.5 \mathrm{~nm}$ as shown in Figure 4.

With the increasing of $\mathrm{Mn}$ concentration in $\mathrm{ZnO}$ nanoparticles, the position of the absorption spectra is shifted towards the lower wavelength side or known as blue-shifted which is correlated to the change in the optical band gap value. The band gap energy of undoped and Mn-doped $\mathrm{ZnO}$ nanoparticles could be determined using the following formula: $E_{\mathrm{bg}}=h c / \lambda$, where $E_{\mathrm{bg}}$ is the band gap energy, $h$ is Planck's constant $\left(4.135667 \times 10^{-15} \mathrm{eV} \mathrm{s}\right), c$ is the velocity of light $\left(2.997924 \times 10^{8} \mathrm{~m} / \mathrm{s}\right)$, and $\lambda$ is the absorption wavelength $(\mathrm{nm})[11]$. The value of the band gap obtained for undoped $\mathrm{ZnO}$ is $3.31 \mathrm{eV}$ and it starts increasing for 3, 5, 10, and $15 \mathrm{~mol} \%$ samples as $3.35,3.38,3.40$, and $3.42 \mathrm{eV}$, respectively.

Generally, blueshifted in the band gap was due to Mn doping in $\mathrm{ZnO}$ nanoparticles with the replacement of $\mathrm{Zn}^{2+}$ ions in the $\mathrm{ZnO}$ lattice by $\mathrm{Mn}^{2+}$ ions. This indicates that the band gap of $\mathrm{ZnO}$ nanoparticles increases with the increasing doping concentration of $\mathrm{Mn}^{2+}$ ion. Furthermore, the blueshifted

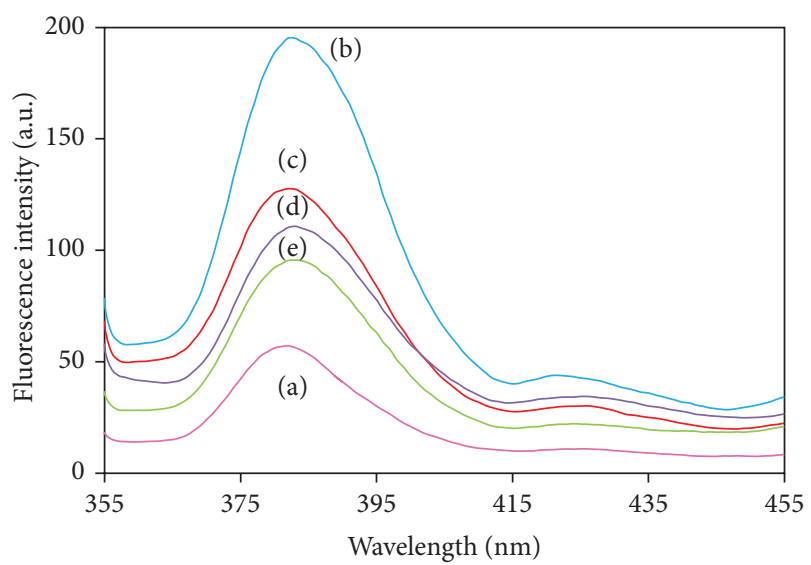

FIGURE 5: Fluorescence spectra of $\mathrm{Mn}$-doped $\mathrm{ZnO}$ nanoparticles with (a) pure $\mathrm{ZnO}$, (b) $3 \mathrm{~mol} \%$, (c) $5 \mathrm{~mol} \%$, (d) $10 \mathrm{~mol} \%$, and (e) $15 \mathrm{~mol} \%$.

in the band gap energy with increasing the amount of $\mathrm{Mn}$ doping concentration can be defined as the separation in energy between the top of the valence bond and the unoccupied energy states in the conduction band [13].

The fluorescence spectrum of undoped $\mathrm{ZnO}$ nanoparticles was taken into account for the comparison of fluorescence intensity between the undoped and Mn-doped $\mathrm{ZnO}$ nanoparticles. From the studies, it was known that $\mathrm{ZnO}$ tends to produce intrinsic defects such as interstitial zinc and oxygen vacancy and these defects will certainly affect the fluorescence behaviour of $\mathrm{ZnO}$. The fluorescence emission peak shifts are found to be size dependent due to quantum size effect. The shift from the top of the valence band and the bottom of conduction band is contributed as a function of fluorescence emission peaks shift. Normally, it was indicated that a redshift of UV emission as the particle size increases [14]. The intrinsic luminescence properties of $\mathrm{ZnO}$ rely upon the concentration of $\mathrm{Mn}$ doping and thus the fluorescence intensity decreases with the increasing of $\mathrm{Mn}$ dopant concentration and the spectrum related to a Mn dopant concentration of $3 \mathrm{~mol} \%$ shows the maximum of fluorescence intensity which is shown in Figure 5. The increase of fluorescence intensity indicates that the incorporation of $\mathrm{Mn}^{2+}$ ion into $\mathrm{ZnO}$ nanoparticles may suppress some nonradiative recombination of free excitation that is near bandedge emission. Moreover, on doping with $\mathrm{Mn}$, the surface traps are eventually quenched which is correlated to the reduction in the surface traps. Moreover, higher concentration of Mn may induce a high density of defects and thus reduces the intensity of emitted light [15].

\section{Conclusion}

$\mathrm{Mn}$-doped $\mathrm{ZnO}$ nanoparticles have been successfully synthesized through coprecipitation method. The effects of manganese dopant concentrations $(3 \mathrm{~mol} \%, 5 \mathrm{~mol} \%, 10 \mathrm{~mol} \%$, $15 \mathrm{~mol} \%$, and $20 \mathrm{~mol} \%$ ) on the composition, morphologies and optical properties of $\mathrm{Mn}$-doped $\mathrm{ZnO}$ nanoparticles have been investigated through EDX, FTIR, SEM, UV-visible spectroscopy, and fluorescence spectra. 


\section{Conflict of Interests}

The authors declare that they have no conflict of interests regarding the publication of this paper.

\section{Acknowledgment}

The authors would like to thank the University of Malaya for sponsoring this work under the University Malaya Research Grant (UMRG RP022-2012A) and the Bright Sparks Program.

\section{References}

[1] H. D. Raval and J. M. Gohil, "Nanotechnology in water treatment: an emerging trend," International Journal of Nuclear Desalination, vol. 4, no. 2, pp. 184-188, 2010.

[2] J. Iqbal, X. Liu, A. Majid, and R. Yu, "Synthesis and physical properties of $\mathrm{Mn}$ doped $\mathrm{ZnO}$ dilute magnetic semiconductor nanostructures," Journal of Superconductivity and Novel Magnetism, vol. 24, no. 1-2, pp. 699-704, 2011.

[3] L. W. Wang, Z. Xu, F. J. Zhang, S. L. Zhao, and L. F. Lu, "Structure, optical, and magnetic properties of $\mathrm{Mn}$-doped $\mathrm{ZnO}$ films prepared by sputtering," International Journal of Minerals, Metallurgy and Materials, vol. 17, no. 4, pp. 475-480, 2010.

[4] W. Shi-Wei, Z. Ming-Yuan, Z. Min et al., "Effects of pulsed magnetic field on $\mathrm{Mn}$-doped $\mathrm{ZnO}$ diluted magnetic semiconductor prepared by hydrothermal method," Acta Physica Sinica, vol. 61, no. 19, Article ID 198103, 2012.

[5] X. X. Yan and G. Y. Xu, "Effect of sintering atmosphere on the electrical and optical properties of $(\mathrm{ZnO}) 1-\mathrm{x}(\mathrm{MnO} 2) \mathrm{x}$ NTCR ceramics," Physica B, vol. 404, no. 16, pp. 2377-2381, 2009.

[6] Y. Abdollahi, A. Abdullah, Z. Zainal, and N. Yusof, "Synthesis and characterization of Manganese doped $\mathrm{ZnO}$ nanoparticles," International Journal of Basic and Applied Sciences, vol. 11, no. 4, pp. 62-69, 2011.

[7] B. Soni, M. P. Deshpande, S. Bhatt, N. Garg, N. Pandya, and S. $\mathrm{H}$. Chaki, "Influence of $\mathrm{Mn}$ doping on optical properties of $\mathrm{ZnO}$ nanoparticles synthesized by microwave irradiation," Journal of Optics, vol. 42, no. 4, pp. 328-334, 2013.

[8] O. D. Jayakumar, H. G. Salunke, R. M. Kadam, M. Mohapatra, G. Yaswant, and S. K. Kulshreshtha, "Magnetism in Mn-doped $\mathrm{ZnO}$ nanoparticles prepared by a co-precipitation method," Nanotechnology, vol. 17, no. 5, pp. 1278-1285, 2006.

[9] M. Yang, Z. X. Guo, K. H. Qiu et al., "Synthesis and characterization of Mn-doped ZnO column arrays," Applied Surface Science, vol. 256, no. 13, pp. 4201-4205, 2010.

[10] S. Senthilkumaar, K. Rajendran, S. Banerjee, T. K. Chini, and V. Sengodan, "Influence of Mn doping on the microstructure and optical property of ZnO," Materials Science in Semiconductor Processing, vol. 11, no. 1, pp. 6-12, 2008.

[11] M. Y. Hao, S. Y. Lou, S. M. Zhou, R. J. Yuan, G. Y. Zhu, and N. Li, "Structural, optical, and magnetic studies of manganesedoped zinc oxide hierarchical microspheres by self-assembly of nanoparticles," Nanoscale Research Letters, vol. 7, no. 100, pp. 113, 2012.

[12] D. Wu, Z. Huang, G. Yin et al., "Preparation, structure and properties of Mn-doped $\mathrm{ZnO}$ rod arrays," CrystEngComm, vol. 12, no. 1, pp. 192-198, 2010.

[13] R. Viswanatha, S. Sapra, S. S. Gupta et al., "Synthesis and characterization of Mn-doped ZnO nanocrystals," Journal of Physical Chemistry B, vol. 108, no. 20, pp. 6303-6310, 2004.
[14] L. Irimpan, V. P. N. Nampoori, P. Radhakrishnan, A. Deepthy, and B. Krishnan, "Size dependent fluorescence spectroscopy of nanocolloids of ZnO," Journal of Applied Physics, vol. 102, no. 6, Article ID 063524, 2007.

[15] F. I. Ezema and U. O. A. Nwankwo, "Effect of concentration of Mn dopant ions on the structural and optical properties of zinc oxide crystals," Digest Journal of Nanomaterials and Biostructures, vol. 6, no. 1, pp. 271-278, 2011. 

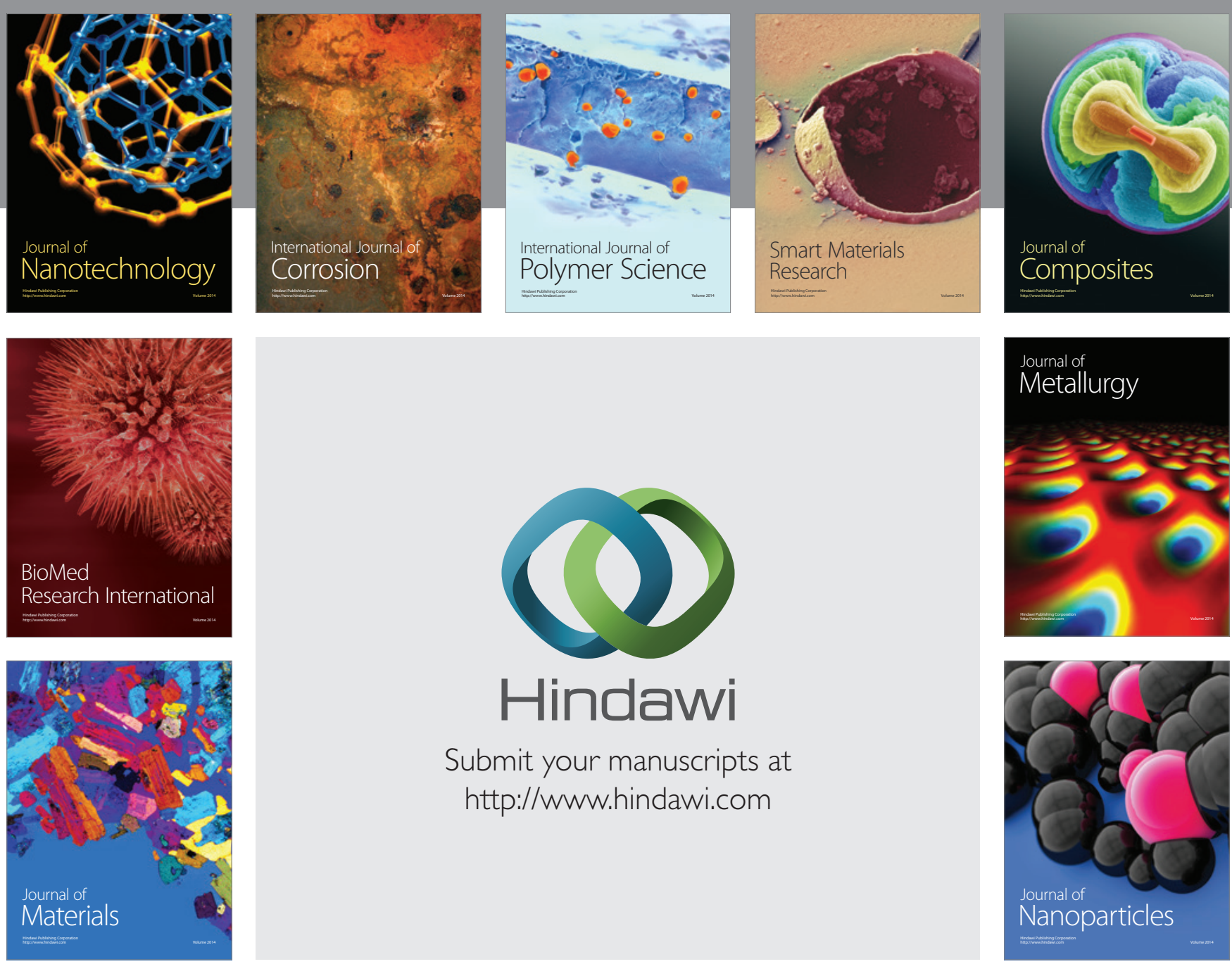

Submit your manuscripts at http://www.hindawi.com
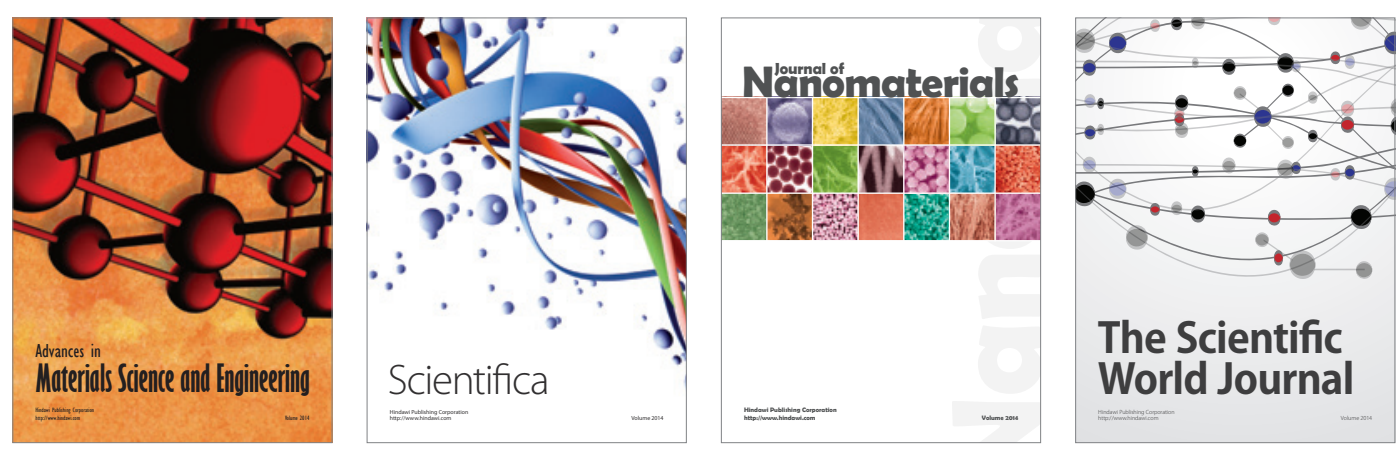

\section{The Scientific World Journal}
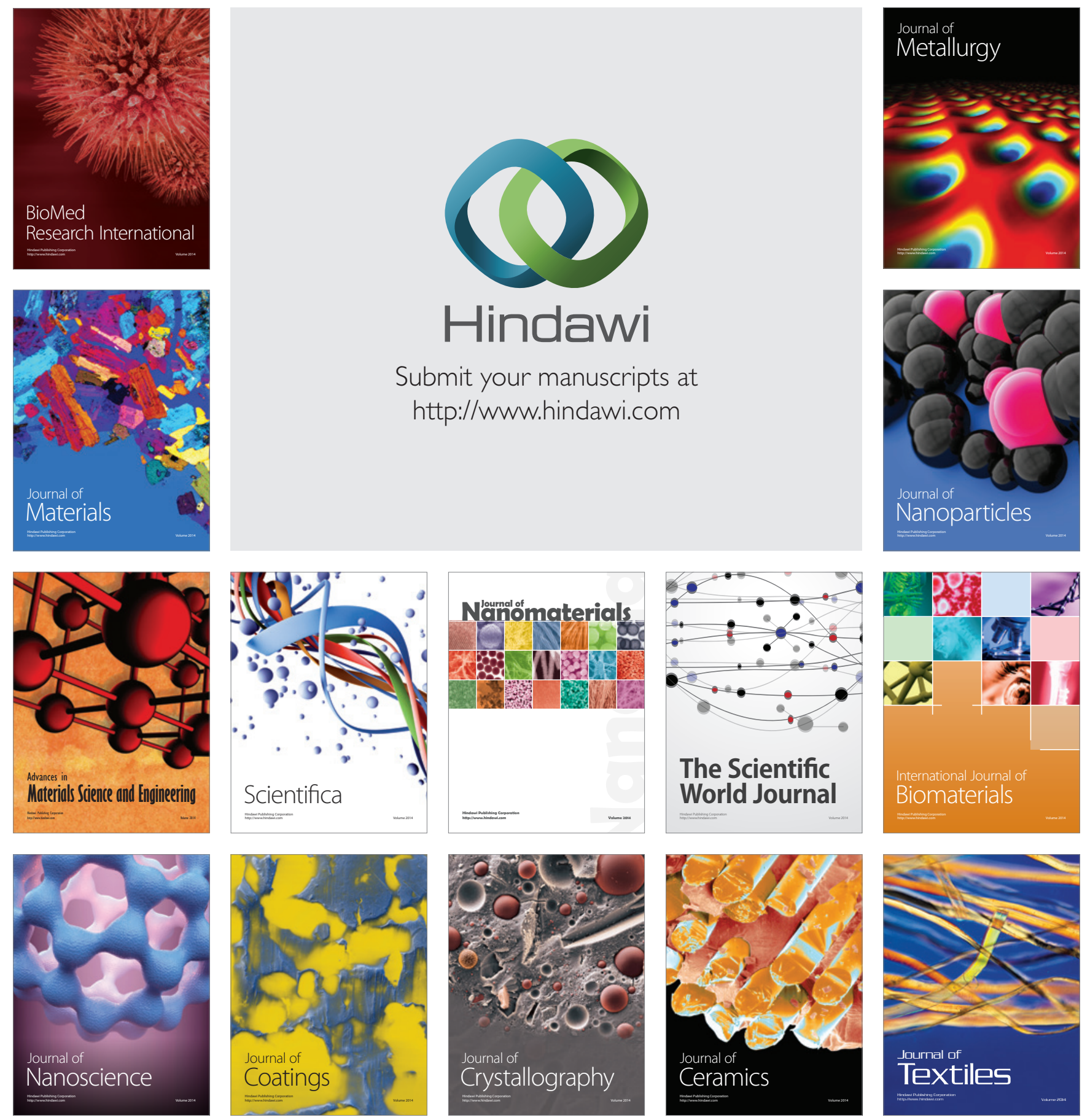